\title{
Potential antioxidants and tyrosinase inhibitors from synthetic polyphenolic deoxybenzoins
}

\author{
Lean-Teik $\mathrm{Ng}^{\mathrm{a}}$, Horng-Huey $\mathrm{Ko}^{\mathrm{b}}$, Tzy-Ming $\mathrm{Lu}^{\mathrm{c}, *}$ \\ a Department of Agricultural Chemistry, National Taiwan University, Taipei, Taiwan \\ ${ }^{\mathrm{b}}$ Department of Fragrance and Cosmetic Science, Kaohsiung Medical University, Kaohsiung, Taiwan \\ c Department of Pharmacy, Tajen University, 20 Wei-Shin Rd, Yanpu, Pingtung 907, Taiwan
}

\section{A R T I C L E I N F O}

\section{Article history:}

Received 2 April 2009

Revised 8 May 2009

Accepted 9 May 2009

Available online 15 May 2009

\section{Keywords:}

Antioxidant

Deoxybenzoin

Phytoestrogen

Polyphenol

Tyrosinase

\begin{abstract}
A B S T R A C T
Deoxybenzoins (DOBs) are one-pot synthetic precursors of isoflavones with feature analogous to those beneficial polyphenols such as resveratrol (stilbene) and phloretin (dihydrochalcone). In this study, seventeen polyphenolic DOBs were synthesized and evaluated by various antioxidant assays and tyrosinase inhibitory effect in vitro. Results displayed that these DOBs are powerful antioxidants; for example, 2,3,4trihydroxy-3', $4^{\prime}$-dimethoxydeoxybenzoin possesses an excellent anti-lipid peroxidation activity $\left(\mathrm{IC}_{50}=0.72 \pm 0.16 \mu \mathrm{M}\right)$, whilst 2,4,4,5-tetrahydroxydeoxybenzoin showed good DPPH radical scavenging activity $\left(\mathrm{IC}_{50}=0.69 \pm 0.04 \mu \mathrm{M}\right)$, which were better than Trolox and vitamin C. Besides exhibiting a weak metal chelating effect, these DOBs were effective in scavenging $\mathrm{ABTS}^{+}$and superoxide anion $\left(\mathrm{O}_{2}{ }^{-{ }^{-}}\right)$radicals. DOBs also exhibited potent mushroom tyrosinase inhibitory activity; for example 2,3,4'-trihydroxy4-methoxydeoxybenzoin displayed stable and significant inhibitory effect on tyrosinase activity, with $\mathrm{IC}_{50}$ values $43.37,43.10$ and $46.10 \mu \mathrm{M}$ at incubation intervals of $0.5,1.5$, and $2.5 \mathrm{~h}$, respectively. These results suggest that, with the advantage of being readily synthesizable small molecules, DOBs can be potentially developed into clinical and industrial antioxidants.
\end{abstract}

Crown Copyright $\odot 2009$ Published by Elsevier Ltd. All rights reserved.

\section{Introduction}

Deoxybenzoins (DOBs) are precursors for one-pot synthesis of isoflavones ${ }^{1-3}$ and can be recovered from the later by alkali hydrolysis. ${ }^{4}$ These compounds closely related to angolensinoids ( $\alpha$-methyldeoxybenzoins), which are known to be reductive metabolites of isoflavones by intestinal microflora both in vitro and in vivo. ${ }^{5-9}$ Structurally, DOBs can be described as the abridged dihydrochalcone (keto form) and $\alpha$-hydroxystilbene (enol form) (Fig. 1).

Soy isoflavones and resveratrol (stilbene) are well known phytoestrogens with antioxidant, cardiovascular protection, cancer chemopreventive and other properties. ${ }^{10,11}$ Furthermore, dihydrochalcones, such as phloretin ${ }^{12,13}$ and synthetic $2^{\prime}, 5^{\prime}-$ dihydroxydihydrochalcone, ${ }^{14}$ and synthetic polyphenolic chalcones ${ }^{15}$ have been demonstrated to be potential antioxidants and/ or anti-inflammatory agents. Although DOBs have been reported to have various interesting pharmacological properties, they have long been neglected until recently. The 2,4,4'-trihydroxydeoxybenzoin (2), synthetic precursor of daidzein, has been reported as

\footnotetext{
* Corresponding author. Tel.: +886 8 7624002x320; fax: +886 87625308 .

E-mail address: cmlu@mail.tajen.edu.tw (T.-M. Lu).
}

a phytoestrogen with more potent estrogenic receptor (ER) binding capability than daidzein, and was shown to be a selective ER $\beta$ agonist. ${ }^{16}$ Another notable compound, 2,4,6-trihydroxy-4'-methoxydeoxybenzoin (15), was reported to be a potential agent for treating severe allergic and inflammatory disorders, as it exhibited potent inhibitory effects on tyrosine kinases SYK and BTK, IgE receptor/ FceRI-mediated mast cell degranulation and leukotriene $\mathrm{C}_{4}$ release, and UVB-induced human keratinocyte prostaglandin $\mathrm{E}_{2}$ release. ${ }^{17}$ Other related derivatives of DOBs have also recently been studied for anti-bacterial activities. ${ }^{18,19}$

Antioxidant therapies have been increasingly recognized to be a potential strategy for preventing acute CNS injury, ${ }^{20}$ cardiovascular diseases $^{21}$ and asthma. ${ }^{22}$ In addition, applications of antioxidants as preservative in food industry ${ }^{23}$ and skin-protective ingredients in cosmetics are also receiving increasing attention and interests. ${ }^{24}$ DOBs are small molecules with great potential for development as antioxidants due to their structural analogousness to known natural products with therapeutic benefits (Fig. 1).

In this study, 17 polyphenolic DOBs were synthesized and evaluated for their antioxidant activities by various assays including anti-lipid peroxidation, metal chelating, reducing power, and free radical scavenging such as $\mathrm{ABTS}^{+}$, DPPH and superoxide anion. In addition, selected DOBs were also evaluated for mushroom antityrosinase inhibitory activity since antioxidants with whitening effect can be potentially used as cosmetic ingredients. 


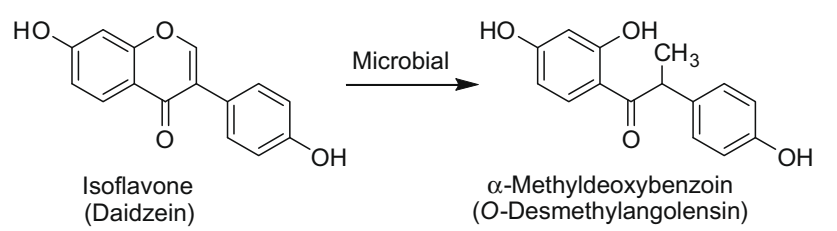

$\mathrm{OH}^{-} \downarrow$ Cyclization

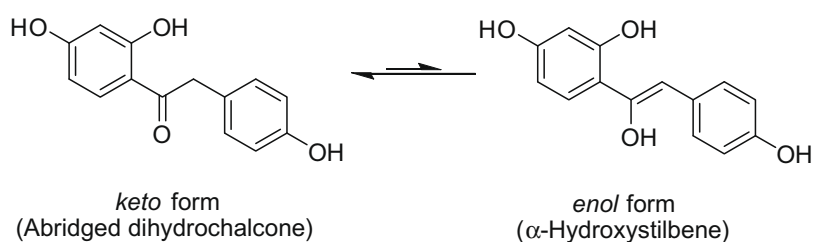

2,4,4'-Trihydroxydeoxybenzoin
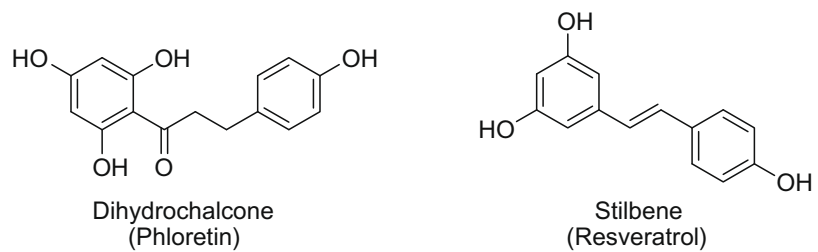

Figure 1. Analogous structures of the DOBs.

\section{Results and discussion}

\subsection{Chemistry}

The synthesis of DOBs was convenient and facile by following the methods of Wähälä and Hase $^{1}$ and/or Balasubramanian et $a^{2,3}$ as shown in Scheme 1 . Seventeen including four newly synthesized (4-6 and 13) poly-oxygenated DOBs were obtained and isolated in gram quantity (yields: 43.4-92.4\%) as depicted (Table 1).

\subsection{Biological assays}

DOBs were evaluated for antioxidant activities including anti-lipid peroxidation, ${ }^{25}$ metal chelating, ${ }^{26}$ reducing power, ${ }^{27}$ and several free radical scavenging assays such as ABTS ${ }^{+},{ }^{28} \mathrm{DPPH}^{\circ},{ }^{26}$ and $\mathrm{O}_{2} \cdot{ }^{-}{ }^{29}$ These assays are commonly applied in the preliminary evaluation of natural product antioxidants, food additives, and cosmetic ingredients. Based on their structural analogousness to resveratrol, which is an effective tyrosinase inhibitor, ${ }^{30}$ selected DOBs were subjected to the mushroom tyrosinase inhibitory assay.
Table 1

Substitution pattern of polyphenolic DOBs 1-17<smiles>[R]c1ccc(CC(=O)c2cc([R])c([R])c([R])c2[R])cc1[R]</smiles>

\begin{tabular}{|c|c|c|c|c|c|c|c|c|}
\hline Entry & Formula & $\mathrm{R}^{1}$ & $\mathrm{R}^{2}$ & $\mathrm{R}^{3}$ & $\mathrm{R}^{4}$ & $\mathrm{R}^{5}$ & $\mathrm{R}^{6}$ & $\mathrm{R}^{7}$ \\
\hline 1 & $\mathrm{C}_{15} \mathrm{H}_{14} \mathrm{O}_{4}$ & $\mathrm{OH}$ & $\mathrm{H}$ & $\mathrm{OH}$ & $\mathrm{H}$ & $\mathrm{H}$ & $\mathrm{H}$ & OMe \\
\hline 2 & $\mathrm{C}_{14} \mathrm{H}_{12} \mathrm{O}_{4}$ & $\mathrm{OH}$ & $\mathrm{H}$ & $\mathrm{OH}$ & $\mathrm{H}$ & $\mathrm{H}$ & $\mathrm{H}$ & $\mathrm{OH}$ \\
\hline 3 & $\mathrm{C}_{16} \mathrm{H}_{16} \mathrm{O}_{5}$ & $\mathrm{OH}$ & $\mathrm{H}$ & $\mathrm{OH}$ & $\mathrm{H}$ & $\mathrm{H}$ & OMe & OMe \\
\hline $4^{a}$ & $\mathrm{C}_{15} \mathrm{H}_{14} \mathrm{O}_{4}$ & $\mathrm{H}$ & $\mathrm{OH}$ & $\mathrm{OH}$ & $\mathrm{H}$ & $\mathrm{H}$ & $\mathrm{H}$ & OMe \\
\hline $5^{a}$ & $\mathrm{C}_{16} \mathrm{H}_{16} \mathrm{O}_{5}$ & $\mathrm{H}$ & $\mathrm{OH}$ & $\mathrm{OH}$ & $\mathrm{H}$ & $\mathrm{H}$ & OMe & OMe \\
\hline $6^{\mathrm{a}}$ & $\mathrm{C}_{17} \mathrm{H}_{18} \mathrm{O}_{4}$ & $\mathrm{OH}$ & Me & $\mathrm{Me}$ & $\mathrm{OH}$ & $\mathrm{H}$ & $\mathrm{H}$ & OMe \\
\hline 7 & $\mathrm{C}_{15} \mathrm{H}_{14} \mathrm{O}_{4}$ & $\mathrm{OH}$ & $\mathrm{H}$ & OMe & $\mathrm{OH}$ & $\mathrm{H}$ & $\mathrm{H}$ & $\mathrm{H}$ \\
\hline 8 & $\mathrm{C}_{15} \mathrm{H}_{14} \mathrm{O}_{5}$ & $\mathrm{OH}$ & $\mathrm{H}$ & $\mathrm{OH}$ & $\mathrm{OH}$ & $\mathrm{H}$ & $\mathrm{H}$ & OMe \\
\hline 9 & $\mathrm{C}_{14} \mathrm{H}_{12} \mathrm{O}_{5}$ & $\mathrm{OH}$ & $\mathrm{H}$ & $\mathrm{OH}$ & $\mathrm{OH}$ & $\mathrm{H}$ & $\mathrm{H}$ & $\mathrm{OH}$ \\
\hline 10 & $\mathrm{C}_{15} \mathrm{H}_{14} \mathrm{O}_{5}$ & $\mathrm{OH}$ & $\mathrm{OH}$ & $\mathrm{OH}$ & $\mathrm{H}$ & $\mathrm{H}$ & $\mathrm{H}$ & OMe \\
\hline 11 & $\mathrm{C}_{15} \mathrm{H}_{12} \mathrm{O}_{5}$ & $\mathrm{OH}$ & $\mathrm{OH}$ & $\mathrm{OH}$ & $\mathrm{H}$ & $\mathrm{H}$ & $\mathrm{H}$ & $\mathrm{OH}$ \\
\hline 12 & $\mathrm{C}_{16} \mathrm{H}_{16} \mathrm{O}_{6}$ & $\mathrm{OH}$ & $\mathrm{OH}$ & $\mathrm{OH}$ & $\mathrm{H}$ & $\mathrm{H}$ & OMe & OMe \\
\hline $13^{a}$ & $\mathrm{C}_{15} \mathrm{H}_{14} \mathrm{O}_{5}$ & $\mathrm{OH}$ & $\mathrm{OH}$ & OMe & $\mathrm{H}$ & $\mathrm{H}$ & $\mathrm{H}$ & $\mathrm{OH}$ \\
\hline 14 & $\mathrm{C}_{14} \mathrm{H}_{12} \mathrm{O}_{4}$ & $\mathrm{OH}$ & $\mathrm{H}$ & $\mathrm{OH}$ & $\mathrm{H}$ & $\mathrm{OH}$ & $\mathrm{H}$ & $\mathrm{H}$ \\
\hline 15 & $\mathrm{C}_{15} \mathrm{H}_{14} \mathrm{O}_{5}$ & $\mathrm{OH}$ & $\mathrm{H}$ & $\mathrm{OH}$ & $\mathrm{H}$ & $\mathrm{OH}$ & $\mathrm{H}$ & OMe \\
\hline 16 & $\mathrm{C}_{14} \mathrm{H}_{12} \mathrm{O}_{5}$ & $\mathrm{OH}$ & $\mathrm{H}$ & $\mathrm{OH}$ & $\mathrm{H}$ & $\mathrm{OH}$ & $\mathrm{H}$ & $\mathrm{OH}$ \\
\hline 17 & $\mathrm{C}_{16} \mathrm{H}_{16} \mathrm{O}_{6}$ & $\mathrm{OH}$ & $\mathrm{H}$ & $\mathrm{OH}$ & $\mathrm{H}$ & $\mathrm{OH}$ & OMe & $\mathrm{OMe}$ \\
\hline
\end{tabular}

\subsubsection{Anti-lipid peroxidation activity of DOBs}

Table 2 (column 2) showed the anti-lipid peroxidation activity of various DOBs. It was found that DOB 12 possessed the most potent activity $\left(\mathrm{IC}_{50}=0.72 \pm 0.16 \mu \mathrm{M}\right)$, which was about five times more potent than Trolox $\left(\mathrm{IC}_{50}=3.68 \pm 0.64 \mu \mathrm{M}\right)$. This result explains that the poly-hydroxylated ring A of DOB can be an active anti-lipid peroxidation skeleton. However, the substitution of ring B favored the more lipophilic 4'-methoxylated, 3',4'-dimethoxylated or unsubstituted phenyl, than the hydrophilic $4^{\prime}$-hydroxyphenyl. It is possible that the lipophilic ring $B$ can enhance the contact of these antioxidants with lipid, and consequently resulting in an efficient termination of the chain reaction.

\subsubsection{Metal ion chelating activity of DOBs}

All DOBs tested showed a weak metal chelating effect ( $\mathrm{IC}_{50}$ values $>1500 \mu \mathrm{M}$ ), with the exception of DOB 10, of which the $\mathrm{IC}_{50}$ value was $1246.79 \pm 5.66 \mu \mathrm{M}$ (Table 2 , column 6 ). This suggests that the anti-lipid peroxidation effects of these compounds were achieved via radical scavenging rather than the metal chelating property.

\subsubsection{Reducing power of DOBs}

Results showed that DOBs 5, 7-11 and $\mathbf{1 3}$ possessed the greatest reducing power, especially DOB $13\left(\mathrm{IC}_{50}=43.72 \pm 2.66 \mu \mathrm{M}\right)$<smiles>[R]CC(C)C(=O)O</smiles> 
Table 2

$\mathrm{IC}_{50}$ values of DOBs in antioxidant activities

\begin{tabular}{|c|c|c|c|c|c|c|}
\hline \multirow[t]{2}{*}{ DOBs } & \multicolumn{6}{|c|}{$\mathrm{IC}_{50}(\mu \mathrm{M})$} \\
\hline & $\mathrm{POV}^{\mathrm{a}}$ & ABTS & DPPH & SOD-like & Metal chelation & Reducing power \\
\hline 1 & $7.33 \pm 0.31$ & $62.64 \pm 4.19$ & $57.40 \pm 5.08$ & $35.19 \pm 1.32$ & $>1500$ & $>1000$ \\
\hline 2 & $25.53 \pm 2.87$ & $30.49 \pm 3.52$ & $25.20 \pm 2.21$ & $113.65 \pm 2.58$ & $>1500$ & $499.55 \pm 74.30$ \\
\hline 3 & $1.84 \pm 0.59$ & $41.94 \pm 1.49$ & $35.10 \pm 1.11$ & $89.34 \pm 1.98$ & $>1500$ & $742.99 \pm 14.20$ \\
\hline 4 & $6.47 \pm 0.54$ & $17.83 \pm 2.02$ & $75.93 \pm 6.36$ & $121.43 \pm 3.72$ & $>1500$ & $>1000$ \\
\hline 5 & $24.93 \pm 2.40$ & $42.67 \pm 1.04$ & $2.53 \pm 0.17$ & $110.59 \pm 4.79$ & $>1500$ & $112.95 \pm 1.02$ \\
\hline 6 & $20.84 \pm 1.68$ & $41.68 \pm 2.48$ & $21.92 \pm 1.40$ & $39.02 \pm 2.03$ & $>1500$ & $147.45 \pm 3.29$ \\
\hline 7 & $6.20 \pm 0.10$ & $36.01 \pm 1.90$ & $20.27 \pm 1.24$ & $54.57 \pm 3.14$ & $>1500$ & $81.16 \pm 6.05$ \\
\hline 8 & $10.69 \pm 0.55$ & $39.60 \pm 1.35$ & $21.46 \pm 1.17$ & $68.18 \pm 4.45$ & $>1500$ & $102.88 \pm 10.29$ \\
\hline 9 & $88.38 \pm 5.15$ & $46.42 \pm 1.35$ & $0.69 \pm 0.04$ & $58.62 \pm 1.77$ & $>1500$ & $68.54 \pm 2.38$ \\
\hline 10 & $13.28 \pm 1.82$ & $50.69 \pm 2.26$ & $21.64 \pm 1.53$ & $28.25 \pm 0.58$ & $1246.79 \pm 5.66$ & $120.22 \pm 6.13$ \\
\hline 11 & $178.38 \pm 10.02$ & $12.88 \pm 1.69$ & $5.69 \pm 0.69$ & $115.46 \pm 3.81$ & $>1500$ & $115.27 \pm 3.96$ \\
\hline 12 & $0.72 \pm 0.16$ & $41.58 \pm 1.12$ & $4.34 \pm 0.95$ & $82.83 \pm 3.62$ & $>1500$ & $320.95 \pm 5.36$ \\
\hline 13 & $85.00 \pm 7.52$ & $50.51 \pm 0.55$ & $25.66 \pm 1.82$ & $96.82 \pm 3.28$ & $>1500$ & $43.72 \pm 2.66$ \\
\hline 14 & $13.36 \pm 0.70$ & $46.43 \pm 1.48$ & $12.25 \pm 0.90$ & $106.15 \pm 6.43$ & $>1500$ & $275.34 \pm 21.14$ \\
\hline 15 & $2.12 \pm 0.15$ & $61.61 \pm 2.81$ & $10.84 \pm 1.57$ & $31.61 \pm 0.99$ & $>1500$ & $231.93 \pm 9.53$ \\
\hline 16 & $37.42 \pm 2.54$ & $27.35 \pm 2.62$ & $22.77 \pm 1.46$ & $109.15 \pm 5.08$ & $>1500$ & $146.77 \pm 3.23$ \\
\hline 17 & $27.04 \pm 1.32$ & $87.24 \pm 2.11$ & $1.35 \pm 0.13$ & $80.72 \pm 3.65$ & $>1500$ & $147.66 \pm 6.25$ \\
\hline Trolox $^{\mathrm{b}}$ & $3.68 \pm 0.64$ & $116.28 \pm 0.72$ & $9.20 \pm 0.44$ & $27.76 \pm 2.36$ & - & $240.56 \pm 4.80$ \\
\hline Ascorbic acid ${ }^{\mathrm{c}}$ & $48.52 \pm 1.42$ & - & $73.69 \pm 1.76$ & $24.15 \pm 0.85$ & - & $131.65 \pm 0.97$ \\
\hline EDTA $^{\mathrm{d}}$ & - & - & - & - & $185.64 \pm 0.34$ & \\
\hline
\end{tabular}

Value are presented as mean \pm SD $(n=3)$.

a POV: anti-lipid peroxidation activity.

b,c,d Positive controls; $50 \%$ inhibition ( $\left(\mathrm{IC}_{50}\right.$ ) values are expressed as $\mu \mathrm{M}$.

which was about three times more potent than ascorbic acid $\left(\mathrm{IC}_{50}=131.65 \pm 0.97 \mu \mathrm{M}\right.$, Table 2 column 7$)$. It is found that DOBs with ortho dihydroxyl ring A, except DOB 4, exert an excellent ferric reducing power. It was also observed that DOBs with the same ring A displayed a better reducing activity when ring B was substituted with $\mathrm{C}-4^{\prime} \mathrm{OH}$.

\subsubsection{ABTS $^{+}$radical scavenging activity of DOBs}

It is surprising to note that all DOBs 1-17 (IC $_{50}$ ranging from $12.88 \pm 1.69 \mu \mathrm{M}$ to $87.24 \pm 2.11 \mu \mathrm{M})$ exhibited a more efficient $\mathrm{ABTS}^{+}{ }^{+}$radical scavenging than Trolox $\left(\mathrm{IC}_{50}=116.3 \pm 0.72 \mu \mathrm{M}\right)(\mathrm{Ta}-$ ble 2 , column 3 ). DOB 11 with an $\mathrm{IC}_{50}$ value of $12.88 \pm 1.69 \mu \mathrm{M}$ was shown to be nearly 10 times more potent than the positive control. This result suggests that DOBs with $C-4^{\prime}$ hydroxylated ring B such as DOBs 2, 11, and 16, would exert a greater potency than those DOBs with the same substitution in ring A. It was shown that DOBs with polyphenol feature possessed promising $\mathrm{ABTS}^{+}$radical scavenging activity. Though $\mathrm{ABTS}^{++}$was a suitable assay for both hydrophilic and lipophilic antioxidants, ${ }^{26}$ the more hydrophilic (polyhydroxylated) DOBs are likely to be better $\mathrm{ABTS}^{++}$radical scavengers. Since phenol is known to be an active functional group for free radical scavenging, suggesting that its property can be one of the main determinants in this activity. It is found that the existence of electron withdrawing ketyl of DOB leading to a more acidic

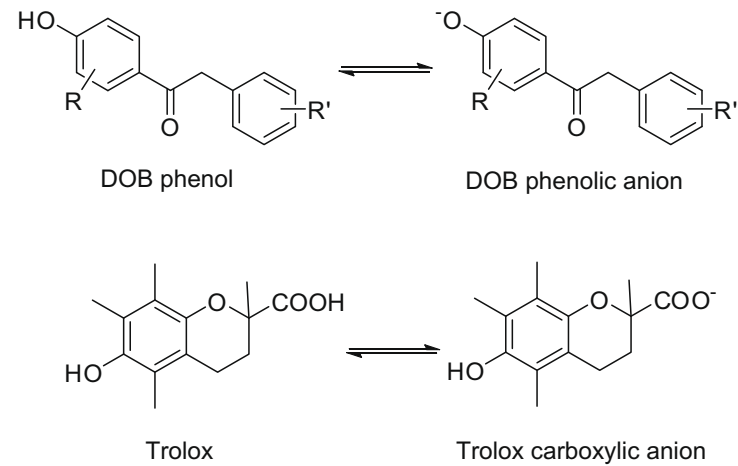

Figure 2. Dissociation of DOB and trolox.
C-4 phenol than that of Trolox. The better free radical scavenging activity of DOBs can be attributed to the capability of ion-pairing that enhanced the contact of phenolic anion with $\mathrm{ABTS}^{+}$. Though Trolox can be dissociated into a carboxylic anion $\left(\mathrm{COO}^{-}\right)$, it was shown to be a lesser effective radical scavenger (Fig. 2).

\subsubsection{DPPH radical scavenging activity of DOBs}

Table 2 (column 4) showed the DPPH radical scavenging activity of DOBs. Besides DOB 4, all other DOBs showed a more active DPPH radical scavenging than ascorbic acid $\left(\mathrm{IC}_{50}=73.69 \pm 1.76 \mu \mathrm{M}\right)$. Generally, when the catechol, pyrogallol or phloroglucinol ring A of DOBs was substituted by a $3^{\prime}, 4^{\prime}$-dimethoxylated ring B (i.e., DOBs 5, 12 and 17), they would exert a greater potency in DPPH radical scavenging power. Among the different DOBs tested, DOB 9 exhibited the most potent DPPH radical scavenging activity $\left(\mathrm{IC}_{50}=0.69 \pm 0.04 \mu \mathrm{M}\right)$, which was about 13 times more potent than Trolox $\left(\mathrm{IC}_{50}=9.20 \pm 0.44 \mu \mathrm{M}\right)$.

\subsubsection{Superoxide radical scavenging activity of DOBs}

As shown in Table 2 (column 5), DOBs displayed a potent superoxide anion radical scavenging activity. Based on the $\mathrm{IC}_{50}$ values,

Table 3

$\mathrm{IC}_{50}$ values of selected DOBs in mushroom tyrosinase inhibitory activity

\begin{tabular}{llll}
\hline Treatment & \multicolumn{3}{c}{$\mathrm{IC}_{50}(\mu \mathrm{M})$} \\
\cline { 2 - 4 } & $30 \mathrm{~min}$ & $90 \mathrm{~min}$ & $150 \mathrm{~min}$ \\
\hline 1 & 78.88 & 160.37 & 181.45 \\
2 & 178.46 & 135.91 & 172.41 \\
3 & 112.06 & 209.14 & 239.70 \\
4 & $>300$ & 167.97 & 177.68 \\
8 & 84.35 & 144.19 & 197.36 \\
10 & $>300$ & 203.32 & 211.92 \\
11 & $>300$ & $>300$ & $>500$ \\
12 & 228.79 & 131.53 & 139.99 \\
13 & 43.37 & 43.10 & 46.10 \\
15 & 71.05 & 213.86 & 230.24 \\
16 & $>300$ & $>300$ & 261.26 \\
Kojic & 132.83 & 225.14 & 438.35 \\
\hline
\end{tabular}

Values are the average of three analyses $(n=3)$

a Positive control; $50 \%$ inhibition ( $\mathrm{IC}_{50}$ ) values are expressed as $\mu \mathrm{M}$. 
DOBs 1, 10 and 15 exhibited a comparable activity as Trolox and vitamin $C$. This result suggests that DOBs with a $p$-methoxylated ring $B$ coupled with resorcinol, pyrogallol, or phloroglucinol ring A (DOBs 1, 10, and 15) could be an effective superoxide anion radical scavenger. However, the anionic expulsion effect of DOBs with $\mathrm{O}_{2}{ }^{--}$can limit the radical scavenging power, which might contribute to the contrasting results from that of the ABTS ${ }^{+}$assay.

\subsubsection{Anti-tyrosinase activity of DOBs}

Mushroom tyrosinase is the common inhibitory target for the evaluation of new whitening agents of cosmetics. Results revealed that most DOBs possessed a greater anti-tyrosinase activity than kojic acid (a commercial whitening ingredient) (Table 3 ). DOBs $\mathbf{1}$, 8, 13 and 15 showed a significant and immediate inhibition at first 30 min of incubation, of which were found to have a meta-dihydroxylated ring A with the exception of DOB 13. This phenomenon is consistent with the demonstrated structural inhibition of resorcinol-containing 1,3-dihydroxyphenylpropionic acid derivatives. ${ }^{31-33}$ In this study, the most active structure was DOB $\mathbf{1 3}$, 2,3,4'-tihydroxy-4-methoxydeoxybenzoin, which showed an almost constant inhibitory effect on tyrosinase at all three incubation intervals. Though 4'-hydroxylated ring B of DOB possesses a similar feature to that of the common enzyme substrate, that is, L-tyrosine, a similar inhibition manner was not observed in DOBs 2, 11 and 16. It is therefore suggested that lipophilic C-4 methoxyl of DOB 13 may play an important role in the inhibition of mushroom tyrosinase activity.

\section{Conclusion}

Taken together, the present study concludes that DOBs with feature analogous to isoflavone, dihydrochalcone and stilbene displayed powerful antioxidant and anti-tyrosinase activities, suggesting that they possess potentials to be developed into clinical therapeutic antioxidants and as new ingredients of cosmetics. Furthermore, the fact that DOBs could be synthesized readily and easily would be another advantage of these compounds in the antioxidant market.

\section{Experimental}

\subsection{Synthesis of DOBs}

The synthesis of DOBs with resorcinol (1-3), catechol (4-5), 2,3dimethylhydroquinone (6), 2-methoxyhydroquinone (7), pyrogallol (10-12) or 3-methoxycatechol (13) ring A (each 0.01 mole) was performed by condensing respective phenols with equivalent quantities of various phenylacetic acids in $\mathrm{BF}_{3}-\mathrm{Et}_{2} \mathrm{O}$ at $80-90{ }^{\circ} \mathrm{C}$ under nitrogen conditioning for $2-3 \mathrm{~h}$ (Scheme 1 , method a). The reaction mixtures were poured into a large quantity of icy NaOAc solution, and then extracted by EtOAc according to Wähälä et al. ${ }^{1}$ However, DOBs with 1,2,4-trihydroxybenzene (8-9) and/or phloroglucinol (14-17) ring A were prepared according to the method as described by Balasubramanian et al. ${ }^{2,3}$ with modification. These phenols ( $0.02 \mathrm{~mol}$ each $)$ and related phenylacetonitriles $(0.01 \mathrm{~mol})$ together with $\mathrm{ZnCl}_{2}(0.01 \mathrm{~mol})$ were pre-suspended in $40 \mathrm{~mL}$ of ethyl ether at $0{ }^{\circ} \mathrm{C}$, then saturated by $\mathrm{HCl}$ (gas, caution!) and stirred for $2 \mathrm{~h}$. After stirring, the reaction mixtures were left to stand over night at ambient temperature. The coagulated products (imines, not isolated) were hydrolyzed by refluxing in $100 \mathrm{~mL} \mathrm{MeOH}-\mathrm{H}_{2} \mathrm{O}(1: 1 ; \mathrm{v} / \mathrm{v})$ for 3-5 h. DOBs (8-9 and 14-17) can be readily crystallized after cooling (Scheme 1, method b). Seventeen polyphenolic DOBs (1-17) were obtained (Table 1) after purifying with column chromatography and/or recrystallized to have satisfying yields (8-9 and 14-17 scaled by respective phenylacetonitriles).

\subsection{General procedures}

Phenylacetic acids, phenylacetonitriles, boron trifluoride etherate $\left(\mathrm{BF}_{3}-\mathrm{Et}_{2} \mathrm{O}\right)$ and related phenols were purchased from Tokyo Chemical Industry (Tokyo, Japan) or Lancaster Synthesis (Morecambe, England). Melting point (uncorrected) was determined by Electrothermal 9100 melting point apparatus (Electrothermal Engineering Ltd, Landon, UK). Mass spectra were recorded on a Bruker Ft Mass Spectrometer (Bruker Daltonics, Bremen, Germany). ${ }^{1} \mathrm{H}(400 \mathrm{MHz})$ and ${ }^{13} \mathrm{C}(100 \mathrm{MHz})$ NMR spectra were recorded on a Varian Mercury-400 spectrometer (Varian Inc., Palo Alto, USA). Mushroom tyrosinase, 2'-azino-bis(3-ethylbenzthiazoline-6-sulfonic acid) (ABTS), 1,1-diphenyl-2-picryl-hydrazyl (DPPH), nitro-blue tetrazolium (NBT), dihydronicotinamide adenine dinucleotide (NADH), ethylenediaminetetraacetic acid (EDTA), Tween-20, ascorbic acid, kojic acid and Trolox were purchased from Sigma Chemical Co. (St. Louis, MO, USA).

\subsubsection{2,4-Dihydroxy-4'-methoxydeoxybenzoin (1)}

$2.27 \mathrm{~g}, 88 \%$ (scale: $8.80 \mathrm{mmol}$ ). $R_{\mathrm{f}}=0.42$ (EtOAc- $n$-hexane-acetone $=2.5: 7: 0.5$ ). Colorless needles (acetone- $n$-hexane), mp $162{ }^{\circ} \mathrm{C} .{ }^{1} \mathrm{H}$ NMR (400 MHz, acetone- $d_{6}$ ): $\delta=3.76$ (3H, s, OMe), 4.12 $\left(2 \mathrm{H}, \mathrm{s}, \mathrm{CH}_{2}\right), 6.33(1 \mathrm{H}, \mathrm{d}, J=2.8 \mathrm{~Hz}, \mathrm{H}-3), 6.45(1 \mathrm{H}, \mathrm{dd}, J=2.4$, $8.8 \mathrm{~Hz}, \mathrm{H}-5), 6.88\left(2 \mathrm{H}, \mathrm{d}, J=8.8 \mathrm{~Hz}, \mathrm{H}-3^{\prime}, 5^{\prime}\right), 7.26(2 \mathrm{H}, \mathrm{d}, J=8.8 \mathrm{~Hz}$, $\left.\mathrm{H}-2^{\prime}, 6^{\prime}\right), 7.96(1 \mathrm{H}, J=8.8 \mathrm{~Hz}, \mathrm{H}-6), 9.48(1 \mathrm{H}, \mathrm{s}, \mathrm{C}-4 \mathrm{OH}), 12.74(1 \mathrm{H}$, s, C-2 OH). ${ }^{13} \mathrm{C}$ NMR $\left(100 \mathrm{MHz}\right.$, acetone- $\left.d_{6}\right): \delta=44.4\left(\mathrm{CH}_{2}\right), 55.6$ (OMe), 103.8 (C-3), 109.1 (C-5), 113.6 (C-1), 114.9 (C-3', 5'), 128.1 (C-1'), 131.5 (C-2', 6'), 159.8 (C-4'), 165.9 (C-2), 166.9 (C-4), 203.9 $(\mathrm{C}=0)$. EIMS $m / z: 258[\mathrm{M}]^{+}, 137[\operatorname{ring} \mathrm{A}+\mathrm{C}=\mathrm{O}]^{+}$. ${ }^{, 16}$

\subsection{2. $2,4,4^{\prime}$-Trihydroxydeoxybenzoin (2)}

$1.32 \mathrm{~g}, 54.1 \%$ (scale: $5.41 \mathrm{mmol}$ ). $R_{\mathrm{f}}=0.38$ (EtOAc- $n$-hexaneacetone $=2.5: 7: 0.5)$. Colorless powders $\left(\mathrm{MeOH}-\mathrm{H}_{2} \mathrm{O}\right)$, mp $194^{\circ} \mathrm{C}$. ${ }^{1} \mathrm{H}$ NMR $\left(400 \mathrm{MHz}\right.$, acetone- $\left.d_{6}\right): \delta=4.16\left(2 \mathrm{H}, \mathrm{s}, \mathrm{CH}_{2}\right), 6.32(1 \mathrm{H}, \mathrm{d}$, $J=2.4 \mathrm{~Hz}, \mathrm{H}-3), 6.43(1 \mathrm{H}, \mathrm{dd}, J=2.4,8.8 \mathrm{~Hz}, \mathrm{H}-5), 6.79(2 \mathrm{H}, \mathrm{d}$, $\left.J=8.8 \mathrm{~Hz}, \mathrm{H}^{\prime} 3^{\prime}, 5^{\prime}\right), 7.16\left(2 \mathrm{H}, \mathrm{d}, J=8.8 \mathrm{~Hz}, \mathrm{H}-2^{\prime}, 6^{\prime}\right), 7.94(1 \mathrm{H}, \mathrm{d}$, $J=8.8 \mathrm{~Hz}, \mathrm{H}-6), 12.75\left(1 \mathrm{H}\right.$, br s, C-2 OH). ${ }^{13} \mathrm{C}$ NMR $(100 \mathrm{MHz}$, acetone- $\left.d_{6}\right): \delta=45.0\left(\mathrm{CH}_{2}\right), 104.3(\mathrm{C}-3), 109.5(\mathrm{C}-5), 114.1(\mathrm{C}-1)$, 116.9 (C-3', 5'), $127.4\left(\mathrm{C}-1^{\prime}\right), 131.9\left(\mathrm{C}-2^{\prime}, 6^{\prime}\right), 135.0$ (C-6), 157.9 $\left(\mathrm{C}-4^{\prime}\right), 166.4(\mathrm{C}-2), 167.4(\mathrm{C}-4), 204.5(\mathrm{C}=0)$. EIMS $m / z: 244[\mathrm{M}]^{+}$, 137 [ring $\mathrm{A}+\mathrm{C}=\mathrm{O}]^{+}$. 1,16

\subsubsection{2,4-Dihydroxy-3', $\mathbf{4}^{\prime}$-dimethoxydeoxybenzoin (3)}

$2.05 \mathrm{~g}, 71.2 \%$ (scale, $7.12 \mathrm{mmol}$ ). $R_{\mathrm{f}}=0.29$ (EtOAc- $n$-hexaneacetone $=2.5: 7: 0.5)$. Colorless needles $(\mathrm{MeOH}), \mathrm{mp} 177-178{ }^{\circ} \mathrm{C}$. ${ }^{1} \mathrm{H}$ NMR $\left(400 \mathrm{MHz}, \mathrm{CDCl}_{3}\right): \delta=3.85(3 \mathrm{H}, \mathrm{s}, \mathrm{OMe}), 3.86(3 \mathrm{H}, \mathrm{s}$, OMe), $4.16\left(2 \mathrm{H}, \mathrm{s}, \mathrm{CH}_{2}\right), 6.37(1 \mathrm{H}, \mathrm{d}, J=2.0 \mathrm{~Hz}, \mathrm{H}-3), 6.39(1 \mathrm{H}, \mathrm{dd}$, $J=2.4,8.8 \mathrm{~Hz}, \mathrm{H}-5), 6.78\left(1 \mathrm{H}, \mathrm{d}, J=2.0 \mathrm{~Hz}, \mathrm{H}-2^{\prime}\right), 6.80(1 \mathrm{H}, \mathrm{dd}$, $\left.J=2.0,8.4 \mathrm{~Hz}, \mathrm{H}-6^{\prime}\right), 6.84\left(1 \mathrm{H}, \mathrm{d}, J=8.4 \mathrm{~Hz}, \mathrm{H}-5^{\prime}\right), 7.76(1 \mathrm{H}, \mathrm{d}$, $J=8.4 \mathrm{~Hz}, \mathrm{H}-6), 12.67(1 \mathrm{H}, \mathrm{s}, \mathrm{C}-2 \mathrm{OH}) .{ }^{13} \mathrm{C} \mathrm{NMR}\left(100 \mathrm{MHz}, \mathrm{CDCl}_{3}\right)$ : $\delta=44.7\left(\mathrm{CH}_{2}\right), 56.1(\mathrm{OMe} \times 2), 103.9(\mathrm{C}-3), 108.1(\mathrm{C}-5), 111.6(\mathrm{C}-$ $\left.5^{\prime}\right), 112.6\left(\mathrm{C}-2^{\prime}\right), 113.7(\mathrm{C}-1), 121.8\left(\mathrm{C}-6^{\prime}\right), 126.9\left(\mathrm{C}-1^{\prime}\right), 133.0(\mathrm{C}-$ 6), 148.3 (C-4'), 149.3 (C-3'), 163.0 (C-2), 165.9 (C-4), 202.5 $(\mathrm{C}=0)$. EIMS m/z: $288[\mathrm{M}]^{+}, 137[\text { ring } \mathrm{A}+\mathrm{C}=\mathrm{O}]^{+3}$.

\subsubsection{3,4-Dihydroxy-4'-methoxydeoxybenzoin (4)}

$1.72 \mathrm{~g}, 66.7 \%$ (scale: $6.67 \mathrm{mmol}$ ). $R_{\mathrm{f}}=0.66$ (EtOAc- $n$-hexaneacetone $=3: 6.5: 0.5)$. Colorless to yellowish needles $\left(\mathrm{MeOH}-\mathrm{H}_{2} \mathrm{O}\right)$, mp $164-165{ }^{\circ} \mathrm{C} .{ }^{1} \mathrm{H}$ NMR $\left(400 \mathrm{MHz}\right.$, acetone- $\left.d_{6}\right): \delta=3.75(3 \mathrm{H}, \mathrm{s}$, OMe), $4.15\left(2 \mathrm{H}, \mathrm{s}, \mathrm{CH}_{2}\right), 6.85\left(2 \mathrm{H}, \mathrm{d}, J=8.8 \mathrm{~Hz}, \mathrm{H}-3^{\prime}, 5^{\prime}\right), 6.90(1 \mathrm{H}$, d, $J=8.4 \mathrm{~Hz}, \mathrm{H}-5), 7.20\left(2 \mathrm{H}, \mathrm{d}, J=8.8 \mathrm{~Hz}, \mathrm{H}-2^{\prime}, 6^{\prime}\right), 7.54(1 \mathrm{H}, \mathrm{d}$, $J=1.2 \mathrm{~Hz}, \mathrm{H}-2), 7.55(1 \mathrm{H}, \mathrm{dd}, J=1.2,8.0 \mathrm{~Hz}, \mathrm{H}-6), 8.36(1 \mathrm{H}, \mathrm{br} \mathrm{s}$, phenolic $\mathrm{OH}), 8.71(1 \mathrm{H}, \mathrm{br}, \mathrm{OH}) .{ }^{13} \mathrm{C}$ NMR $\left(100 \mathrm{MHz}\right.$, acetone- $\left.d_{6}\right)$ : $\delta=45.2\left(\mathrm{CH}_{2}\right), 56.1(\mathrm{OMe}), 115.3\left(\mathrm{C}-3^{\prime}, 5^{\prime}\right), 116.3(\mathrm{C}-2), 116.8(\mathrm{C}-$

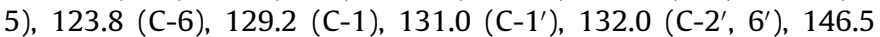
(C-3), 151.7 (C-4), $160.0\left(\mathrm{C}-4^{\prime}\right), 197.3(\mathrm{C}=0)$. ESIMS (+) m/z: 281 
$[\mathrm{M}+\mathrm{Na}]^{+}$; HRESIMS (+) $\mathrm{m} / \mathrm{z}: 281.0792$ (calcd for $\mathrm{C}_{15} \mathrm{H}_{14} \mathrm{O}_{4} \mathrm{Na}=$ 281.0790).

\subsubsection{3,4-Dihydroxy-3', $\mathbf{4}^{\prime}$-dimethoxydeoxybenzoin (5)}

$2.66 \mathrm{~g}, 92.4 \%$ (scale: $9.24 \mathrm{mmol}$ ). $R_{\mathrm{f}}=0.51$ (EtOAc- $n$-hexaneacetone $=2.5: 7: 0.5)$. Yellowish needles $\left(\mathrm{MeOH}-\mathrm{H}_{2} \mathrm{O}\right)$, mp 256$257{ }^{\circ} \mathrm{C} .{ }^{1} \mathrm{H}$ NMR $\left(400 \mathrm{MHz}\right.$, acetone- $d_{6}$ ): $\delta=3.76,3.77$ (each $3 \mathrm{H}, \mathrm{s}$, OMe), $4.14\left(2 \mathrm{H}, \mathrm{s}, \mathrm{CH}_{2}\right), 6.80\left(2 \mathrm{H}, \mathrm{d}, J=2.0,8.8 \mathrm{~Hz}, \mathrm{H}-6^{\prime}\right), 6.85$ $\left(1 \mathrm{H}, \mathrm{d}, J=8.0 \mathrm{~Hz}, \mathrm{H}-5^{\prime}\right), 6.90(2 \mathrm{H}, \mathrm{d}, J=8.0 \mathrm{~Hz}, \mathrm{H}-5), 6.91(1 \mathrm{H}, \mathrm{d}$, $\left.J=2.0 \mathrm{~Hz}, \mathrm{H}-2^{\prime}\right), 7.54(1 \mathrm{H}, \mathrm{d}, J=2.0 \mathrm{~Hz}, \mathrm{H}-2), 7.56(1 \mathrm{H}, \mathrm{dd}, J=2.0$, $8.0 \mathrm{~Hz}, \mathrm{H}-6), 8.49(2 \mathrm{H}, \mathrm{br}, \mathrm{OH}) .{ }^{13} \mathrm{C}$ NMR $\left(100 \mathrm{MHz}\right.$, acetone- $\left.d_{6}\right)$ : $\delta=44.3\left(\mathrm{CH}_{2}\right), 55.4(\mathrm{OMe}), 55.4(\mathrm{OMe}), 112.2\left(\mathrm{C}-5^{\prime}\right), 113.8\left(\mathrm{C}-2^{\prime}\right)$, 115.0 (C-2), 115.5 (C-5), 121.8 (C-6'), 122.6 (C-6), 128.5 (C-1), $129.8\left(\mathrm{C}-1^{\prime}\right), 132.0\left(\mathrm{C}-2^{\prime}, 6^{\prime}\right), 145.2(\mathrm{C}-4), 148.5\left(\mathrm{C}-4^{\prime}\right), 149.6(\mathrm{C}-$ $\left.3^{\prime}\right), 150.3(\mathrm{C}-3), 195.9(\mathrm{C}=\mathrm{O})$. ESIMS $(+) \mathrm{m} / \mathrm{z}$ : $311(\mathrm{M}+\mathrm{Na})$; HRESMS (+) $\mathrm{m} / z: 311.0893$ (calcd for $\mathrm{C}_{16} \mathrm{H}_{16} \mathrm{O}_{5} \mathrm{Na}=311.0895$ ).

\subsubsection{2,5-Dihydroxy-4'-methoxy-3,4-dimethyldeoxybenzoin (6)}

$1.24 \mathrm{~g}, 43.4 \%$ (scale: $4.34 \mathrm{mmol}$ ). $R_{\mathrm{f}}=0.60$ (EtOAc- $n$-hexaneacetone $=2.5: 7: 0.5)$. Colorless needles $(\mathrm{MeOH}), \mathrm{mp} 177-178^{\circ} \mathrm{C}$. ${ }^{1} \mathrm{H}$ NMR $\left(400 \mathrm{MHz}, \mathrm{CDCl}_{3}\right): \delta=2.19(3 \mathrm{H}, \mathrm{s}, \mathrm{Ar}-\mathrm{Me}), 2.22(3 \mathrm{H}, \mathrm{s}$, Ar-Me), $3.78(3 \mathrm{H}, \mathrm{s}, \mathrm{OMe}), 4.11\left(2 \mathrm{H}, \mathrm{s}, \mathrm{CH}_{2}\right), 6.86(2 \mathrm{H}, \mathrm{d}$, $\left.J=8.4 \mathrm{~Hz}, \mathrm{H}-3^{\prime}, 5^{\prime}\right), 7.07(1 \mathrm{H}, \mathrm{s}, \mathrm{H}-6), 7.14\left(2 \mathrm{H}, \mathrm{d}, J=8.4 \mathrm{~Hz}, \mathrm{H}-2^{\prime}\right.$, $\left.6^{\prime}\right), 12.32(1 \mathrm{H}, \mathrm{s}, \mathrm{C}-2 \mathrm{OH}) .{ }^{13} \mathrm{C}$ NMR $\left(100 \mathrm{MHz}, \mathrm{CDCl}_{3}\right): \delta=11.5$ (Ar-Me), 13.0 (Ar-Me), $44.1\left(\mathrm{CH}_{2}\right), 55.3$ (OMe), 111.6 (C-6), 114.2 $\left(\mathrm{C}-3^{\prime}, 5^{\prime}\right), 115.6(\mathrm{C}-1), 126.2(\mathrm{C}-3), 127.1\left(\mathrm{C}-1^{\prime}\right), 130.4\left(\mathrm{C}-2^{\prime}, 6^{\prime}\right)$, 134.5 (C-4), 145.5 (C-5), 155.7 (C-2), $158.6\left(\mathrm{C}-4^{\prime}\right), 203.4(\mathrm{C}=0)$ ). EIMS $m / z$ : $286[\mathrm{M}]^{+}, 165$ [ring $\left.\mathrm{A}+\mathrm{C}=0\right]^{+} ; \operatorname{HRESIMS}(+) \mathrm{m} / \mathrm{z}$ : 309.1101 (calcd for $\mathrm{C}_{15} \mathrm{H}_{14} \mathrm{O}_{5} \mathrm{Na}=309.1103$ ).

\subsubsection{2,5-Dihydroxy-4-methoxydeoxybenzoin (7)}

$2.24 \mathrm{~g}, 86.8 \%$ (scale: $8.68 \mathrm{mmol}$ ). $R_{\mathrm{f}}=0.45$ (EtOAc- $n$-hexaneacetone $=2.5: 7: 0.5)$. Yellowish powders $\left(\mathrm{MeOH}-\mathrm{H}_{2} \mathrm{O}\right)$, mp 154$155^{\circ} \mathrm{C} .{ }^{1} \mathrm{H}$ NMR $\left(400 \mathrm{MHz}, \mathrm{CDCl}_{3}\right.$ ): $\delta=3.91$ (3H, s, OMe), 4.19 $\left(2 \mathrm{H}, \mathrm{s}, \mathrm{CH}_{2}\right), 6.44(1 \mathrm{H}, \mathrm{s}, \mathrm{H}-3), 7.26-7.34$ (total $\left.5 \mathrm{H}, \mathrm{m}, \mathrm{H}-2^{\prime}-6^{\prime}\right)$, $7.33(1 \mathrm{H}, \mathrm{s}, \mathrm{H}-6), 12.47(1 \mathrm{H}, \mathrm{s}, \mathrm{C}-2 \mathrm{OH}) .{ }^{13} \mathrm{C} \mathrm{NMR}\left(100 \mathrm{MHz}, \mathrm{CDCl}_{3}\right)$ : $\delta=45.2\left(\mathrm{CH}_{2}\right), 56.4(\mathrm{OMe}), 100.2(\mathrm{C}-3), 112.0(\mathrm{C}-1), 113.8(\mathrm{C}-6)$, $127.3\left(\mathrm{C}-4^{\prime}\right), 129.0\left(\mathrm{C}-3^{\prime}, 5^{\prime}\right), 129.6\left(\mathrm{C}-2^{\prime}, 6^{\prime}\right), 134.5\left(\mathrm{C}-1^{\prime}\right), 138.3$ (C-5), 154.1 (C-2), 159.8 (C-4), $202.2(\mathrm{C}=0)$. EIMS m/z: $258[\mathrm{M}]^{+}$, $167[\operatorname{ring} \mathrm{A}+\mathrm{C}=\mathrm{O}]^{+34}$

\subsubsection{2,4,5-Trihydroxy-4'-methoxydeoxybenzoin (8)}

$2.18 \mathrm{~g}, 79.6 \%$ (scale: $7.96 \mathrm{mmol}$ ). $R_{\mathrm{f}}=0.24$ (EtOAc- $n$-hexaneacetone $=3: 6.5: 0.5)$. Pinkish needles $\left(\mathrm{MeOH}-\mathrm{H}_{2} \mathrm{O}\right)$, mp 188$189{ }^{\circ} \mathrm{C} .{ }^{1} \mathrm{H}$ NMR $\left(400 \mathrm{MHz}\right.$, acetone- $\left.d_{6}\right): \delta=3.77$ (3H, s, OMe), $4.15\left(2 \mathrm{H}, \mathrm{s}, \mathrm{CH}_{2}\right), 6.36(1 \mathrm{H}, \mathrm{s}, \mathrm{H}-3), 6.88\left(2 \mathrm{H}, \mathrm{d}, J=8.8 \mathrm{~Hz}, \mathrm{H}-3^{\prime}\right.$, $\left.5^{\prime}\right), 7.24\left(2 \mathrm{H}, \mathrm{d}, J=8.8 \mathrm{~Hz}, \mathrm{H}-2^{\prime}, 6^{\prime}\right), 7.42(1 \mathrm{H}, \mathrm{s}, \mathrm{H}-6), 12.42(1 \mathrm{H}, \mathrm{s}$, $\mathrm{C}-2 \mathrm{OH}) .{ }^{13} \mathrm{C}$ NMR $\left(100 \mathrm{MHz}\right.$, acetone- $\left.d_{6}\right): \delta=43.8\left(\mathrm{CH}_{2}\right), 54.8$ (OMe), 103.3 (C-3), 111.4(C-1), 114.1 (C-3', 5'), 115.8(C-6), 127.4 (C-1'), 130.6 (C-2', 6'), 138.1 (C-5), 154.3 (C-4), 158.9 (C-2), 159.8 $\left(\mathrm{C}-4^{\prime}\right), 202.6(\mathrm{C}=\mathrm{O})$. EIMS $\mathrm{m} / \mathrm{z} 274[\mathrm{M}]^{+}, 153\left[\mathrm{ring} \mathrm{A}+\mathrm{C}=\mathrm{O}^{+}{ }^{+}{ }^{34}\right.$

\subsection{9. $2,4,5,4^{\prime}$-Tetrahydroxydeoxybenzoin (9)}

$1.96 \mathrm{~g}, 75.4 \%$ (scale: $7.54 \mathrm{mmol}$ ). $R_{\mathrm{f}}=0.26$ (EtOAc- $n$-hexaneacetone $=4: 5.5: 0.5)$. Colorless needles $\left(\mathrm{MeOH}-\mathrm{H}_{2} \mathrm{O}\right)$, mp 297$299{ }^{\circ} \mathrm{C} .{ }^{1} \mathrm{H}$ NMR $\left(400 \mathrm{MHz}\right.$, acetone- $\left.d_{6}\right): \delta=4.10\left(2 \mathrm{H}, \mathrm{s}, \mathrm{CH}_{2}\right), 6.35$ $(1 \mathrm{H}, \mathrm{s}, \mathrm{H}-3), 6.79\left(2 \mathrm{H}, \mathrm{d}, J=8.8 \mathrm{~Hz}, \mathrm{H}-3^{\prime}, 5^{\prime}\right), 7.15(2 \mathrm{H}, \mathrm{d}$, $\left.J=8.8 \mathrm{~Hz}, \mathrm{H}-2^{\prime}, 6^{\prime}\right), 7.41(1 \mathrm{H}, \mathrm{s}, \mathrm{H}-6), 8.40(3 \mathrm{H}, \mathrm{br}, \mathrm{OH}), 12.44$ $(1 \mathrm{H}, \mathrm{s}, \mathrm{C}-2 \mathrm{OH}) .{ }^{13} \mathrm{C}$ NMR $\left(100 \mathrm{MHz}\right.$, acetone- $\left.d_{6}\right): \delta=43.9\left(\mathrm{CH}_{2}\right)$, 103.3 (C-3), 111.4 (C-1), 115.6 (C-3',5'), 115.8 (C-6), $126.2\left(\mathrm{C}-1^{\prime}\right)$, $130.6\left(\mathrm{C}-2^{\prime}, 6^{\prime}\right), 138.1(\mathrm{C}-5), 154.4(\mathrm{C}-4), 156.5(\mathrm{C}-2), 159.8\left(\mathrm{C}-4^{\prime}\right)$, $202.7(\mathrm{C}=\mathrm{O})$. EIMS m/z: $260[\mathrm{M}]^{+}, 153[\operatorname{ring} \mathrm{A}+\mathrm{C}=\mathrm{O}]^{+} .^{34}$

\subsubsection{0. $2,3,4$-Trihydroxy-4' -methoxydeoxybenzoin (10)}

$2.40 \mathrm{~g}, 87.6 \%$ (scale: $8.76 \mathrm{mmol}$ ). $R_{\mathrm{f}}=0.46$ (EtOAc- $n$-hexaneacetone $=3: 6.5: 0.5)$. Colorless needles $\left(\mathrm{MeOH}-\mathrm{H}_{2} \mathrm{O}\right)$, mp 191-
$192{ }^{\circ} \mathrm{C} .{ }^{1} \mathrm{H}$ NMR $\left(400 \mathrm{MHz}\right.$, acetone- $\left.d_{6}\right): \delta=3.76(3 \mathrm{H}, \mathrm{s}, \mathrm{OMe})$, $4.22\left(2 \mathrm{H}, \mathrm{s}, \mathrm{CH}_{2}\right), 6.48(1 \mathrm{H}, \mathrm{d}, J=8.8 \mathrm{~Hz}, \mathrm{H}-5), 6.87(2 \mathrm{H}, \mathrm{d}$, $\left.J=8.8 \mathrm{~Hz}, \mathrm{H}-3^{\prime}, 5^{\prime}\right), 7.25\left(2 \mathrm{H}, \mathrm{d}, J=8.8 \mathrm{~Hz}, \mathrm{H}-2^{\prime}, 6^{\prime}\right), 7.55(1 \mathrm{H}, \mathrm{d}$, $J=8.4 \mathrm{~Hz}, \mathrm{H}-6), 7.80(1 \mathrm{H}, \mathrm{s}, \mathrm{OH}), 8.66(1 \mathrm{H}, \mathrm{s}, \mathrm{OH}), 12.74(1 \mathrm{H}, \mathrm{s}, \mathrm{C}-$ $2 \mathrm{OH}) \cdot{ }^{13} \mathrm{C}$ NMR $\left(100 \mathrm{MHz}\right.$, acetone- $\left.d_{6}\right): \delta=44.9\left(\mathrm{CH}_{2}\right), 56.1$ (OMe), 109.1 (C-5), 114.4 (C-1), 115.4 (C-3', 5'), 124.8 (C-6), $128.7\left(\mathrm{C}-1^{\prime}\right), 132.0\left(\mathrm{C}-2^{\prime}, 6^{\prime}\right), 133.8(\mathrm{C}-3), 153.4(\mathrm{C}-2), 154.1(\mathrm{C}-4)$, $160.3\left(\mathrm{C}-4^{\prime}\right), 205.1(\mathrm{C}=\mathrm{O})$. ESIMS (+) $\mathrm{m} / z: 275[\mathrm{M}+\mathrm{H}]^{+}{ }^{1,2}$

\subsubsection{1. $2,3,4,4^{\prime}$-Tetrahydroxydeoxybenzoin (11)}

$1.42 \mathrm{~g}, 5.46 \%$ (scale: $54.6 \mathrm{mmol}$ ). $R_{\mathrm{f}}=0.35$ (EtOAc- $n$-hexaneacetone $=4: 5.5: 0.5)$. Colorless needles $\left(\mathrm{MeOH}-\mathrm{H}_{2} \mathrm{O}\right)$, mp 281$282{ }^{\circ} \mathrm{C} .{ }^{1} \mathrm{H}$ NMR $\left(400 \mathrm{MHz}\right.$, acetone- $\left.d_{6}\right): \delta=4.18\left(2 \mathrm{H}, \mathrm{s}, \mathrm{CH}_{2}\right), 6.48$ $(1 \mathrm{H}, \mathrm{d}, J=8.8 \mathrm{~Hz}, \mathrm{H}-5), 6.78\left(2 \mathrm{H}, \mathrm{d}, J=8.8 \mathrm{~Hz}, \mathrm{H}-3^{\prime}, 5^{\prime}\right), 7.16(2 \mathrm{H}$ d, $\left.J=8.8 \mathrm{~Hz}, \mathrm{H}-2^{\prime}, 6^{\prime}\right), 7.55(1 \mathrm{H}, \mathrm{d}, J=8.8 \mathrm{~Hz}, \mathrm{H}-6), 8.27(3 \mathrm{H}, \mathrm{br}$, $\mathrm{OH}), 12.77\left(1 \mathrm{H}\right.$, br s, C-2 OH). ${ }^{13} \mathrm{C}$ NMR $\left(100 \mathrm{MHz}\right.$, acetone- $\left.d_{6}\right)$ : $\delta=43.6\left(\mathrm{CH}_{2}\right), 107.7(\mathrm{C}-5), 113.0(\mathrm{C}-1), 115.5\left(\mathrm{C}-3^{\prime}, 5^{\prime}\right), 123.5(\mathrm{C}-$ 6), $126.1\left(\mathrm{C}-1^{\prime}\right), 130.7\left(\mathrm{C}-2^{\prime}, 6^{\prime}\right), 132.5(\mathrm{C}-3), 152.0(\mathrm{C}-2), 152.8$ (C-4), $156.5\left(\mathrm{C}-4^{\prime}\right), 203.9(\mathrm{C}=0)$. EIMS m/z: $260[\mathrm{M}]^{+}, 153$ [ring $\mathrm{A}+\mathrm{C}=\mathrm{O}]^{+} .1,2,16$

\subsubsection{2,3,4-Trihydroxy-3', $\mathbf{4}^{\prime}$-dimethoxydeoxybenzoin (12)}

$2.42 \mathrm{~g}, 79.6 \%$ (scale: $7.96 \mathrm{mmol}$ ). $R_{\mathrm{f}}=0.43$ (EtOAc- $n$-hexaneacetone $=4: 5.5: 0.5)$. Colorless needles $\left(\mathrm{MeOH}-\mathrm{H}_{2} \mathrm{O}\right)$, mp 166$167{ }^{\circ} \mathrm{C} .{ }^{1} \mathrm{H}$ NMR $\left(400 \mathrm{MHz}\right.$, acetone- $\left.d_{6}\right): \delta=3.76(3 \mathrm{H}, \mathrm{s}, \mathrm{OMe})$, $3.77(3 \mathrm{H}, \mathrm{s}, \mathrm{OMe}), 4.20\left(2 \mathrm{H}, \mathrm{s}, \mathrm{CH}_{2}\right), 6.48(1 \mathrm{H}, \mathrm{d}, J=8.8 \mathrm{~Hz}, \mathrm{H}-5)$ $6.84\left(2 \mathrm{H}, \mathrm{dd}, J=2.0,8.4 \mathrm{~Hz}, \mathrm{H}-6^{\prime}\right), 6.87\left(2 \mathrm{H}, \mathrm{d}, J=8.4 \mathrm{~Hz}, \mathrm{H}-5^{\prime}\right)$, $6.96\left(1 \mathrm{H}, \mathrm{d}, J=2.0 \mathrm{~Hz}, \mathrm{H}-2^{\prime}\right), 7.55(1 \mathrm{H}, \mathrm{d}, J=8.8 \mathrm{~Hz}, \mathrm{H}-6), 7.96$ $(1 \mathrm{H}, \mathrm{br}, \mathrm{OH}), 8.78(1 \mathrm{H}, \mathrm{br}, \mathrm{OH}), 12.74(1 \mathrm{H}, \mathrm{s}, \mathrm{C}-2 \mathrm{OH}) .{ }^{13} \mathrm{C} \mathrm{NMR}$ $\left(100 \mathrm{MHz}\right.$, acetone- $\left.d_{6}\right): \delta=45.3\left(\mathrm{CH}_{2}\right), 56.7(\mathrm{OMe} \times 2), 109.1(\mathrm{C}-$ 5), 113.5 (C-5'), 114.4 (C-1), $115.0\left(\mathrm{C}-2^{\prime}\right), 123.1\left(\mathrm{C}-6^{\prime}\right), 124.7$ (C6), 129.2 (C-1'), 133.9 (C-3), 150.0 (C-2), 151.0 (C-4'), 153.4 (C41), $154.1(\mathrm{C}-4), 205.0(\mathrm{C}=\mathrm{O})$. ESIMS $(+) \mathrm{m} / \mathrm{z}: 305[\mathrm{M}+\mathrm{H}]^{+35}$

\subsubsection{3. $2,3,4$ '-Trihydroxy-4-methoxydeoxybenzoin (13)}

$2.15 \mathrm{~g}, 78.5 \%$ (scale: $7.85 \mathrm{mmol}$ ). $R_{\mathrm{f}}=0.23$ (EtOAc- $n$-hexaneacetone $=3: 6.5: 0.5)$. Colorless powders $\left(\mathrm{MeOH}-\mathrm{H}_{2} \mathrm{O}\right)$, mp 249$250{ }^{\circ} \mathrm{C}$. ${ }^{1} \mathrm{H}$ NMR $\left(400 \mathrm{MHz}\right.$, acetone- $\left.d_{6}\right): \delta=3.91(3 \mathrm{H}, \mathrm{s}, \mathrm{OMe})$, $4.21\left(2 \mathrm{H}, \mathrm{s}, \mathrm{CH}_{2}\right), 6.65(1 \mathrm{H}, \mathrm{d}, J=8.8 \mathrm{~Hz}, \mathrm{H}-5), 6.79(2 \mathrm{H}, \mathrm{d}$, $\left.J=8.4 \mathrm{~Hz}, \mathrm{H}-3^{\prime}, 5^{\prime}\right), 7.16\left(2 \mathrm{H}, \mathrm{d}, J=8.4 \mathrm{~Hz}, \mathrm{H}-2^{\prime}, 6^{\prime}\right), 7.63(1 \mathrm{H}, \mathrm{d}$, $J=8.4 \mathrm{~Hz}, \mathrm{H}-6), 8.24(1 \mathrm{H}, \mathrm{br}, \mathrm{OH}), 12.46(1 \mathrm{H}, \mathrm{br}, \mathrm{C}-2 \mathrm{OH}) .{ }^{13} \mathrm{C}$ NMR $\left(100 \mathrm{MHz}\right.$, acetone- $\left.d_{6}\right): \delta=43.9\left(\mathrm{CH}_{2}\right), 55.8(\mathrm{OMe}), 103.5(\mathrm{C}-$ 5), 114.2 (C-1), 115.5 (C-3', 5'), 122.9 (C-6), $126.1\left(\mathrm{C}-1^{\prime}\right), 130.6$ (C-2', 6'), 134.5 (C-3), 151.9 (C-2), 153.2 (C-4), 156.5 (C-4'), 204.2 $(\mathrm{C}=\mathrm{O})$. ESIMS $(+) \mathrm{m} / z: 297[\mathrm{M}+\mathrm{Na}]^{+}$; HRESIMS (+) $\mathrm{m} / \mathrm{z}: 297.0741$ (calcd for $\mathrm{C}_{15} \mathrm{H}_{14} \mathrm{O}_{5} \mathrm{Na}=297.0739$ ).

\subsubsection{2,4,6-Trihydroxydeoxybenzoin (14)}

$1.77 \mathrm{~g}, 72.5 \%$ (scale: $7.25 \mathrm{mmol}$ ). $R_{\mathrm{f}}=0.26$ (EtOAc- $n$-hexaneacetone $=2.5: 7: 0.5)$. Yellowish granules $\left(\mathrm{MeOH}-\mathrm{H}_{2} \mathrm{O}\right), \mathrm{mp} 164{ }^{\circ} \mathrm{C}$. ${ }^{1} \mathrm{H}$ NMR (400 MHz, acetone- $\left.d_{6}\right): \delta=4.42\left(2 \mathrm{H}, \mathrm{s}, \mathrm{CH}_{2}\right), 5.95(2 \mathrm{H}, \mathrm{s}$, $\mathrm{H}-3,5), 7.21\left(1 \mathrm{H}, \mathrm{m}, J=8.4 \mathrm{~Hz}, \mathrm{H}-4^{\prime}\right), 7.28\left(4 \mathrm{H}, \mathrm{m}, \mathrm{H}-2^{\prime}, 3^{\prime}, 5^{\prime}, 6^{\prime}\right)$, $9.28(1 \mathrm{H}$, br s, phenolic $\mathrm{OH}), 11.74(2 \mathrm{H}$, br s, C-2, 6OH $) .{ }^{13} \mathrm{C}$ NMR $\left(100 \mathrm{MHz}\right.$, acetone- $\left.d_{6}\right): \delta=49.5\left(\mathrm{CH}_{2}\right), 95.3(\mathrm{C}-3,5), 104.5(\mathrm{C}-1)$, 126.5 (C-4'), $128.3\left(\mathrm{C}-3^{\prime}, 5^{\prime}\right), 130.0\left(\mathrm{C}-2^{\prime}, 6^{\prime}\right), 136.4\left(\mathrm{C}-1^{\prime}\right)$ 164.8(C-2, 6), 164.9 (C-4), $203.0(\mathrm{C}=0)$. EIMS m/z: $244[\mathrm{M}]^{+}, 153$ [ring $\mathrm{A}+\mathrm{C}=\mathrm{O}^{+}{ }^{+34}$

\subsubsection{2,4,6-Trihydroxy-4'-methoxydeoxybenzoin (15)}

$2.02 \mathrm{~g}, 73.7 \%$ (scale: $7.37 \mathrm{mmol}$ ). $R_{\mathrm{f}}=0.38$ (EtOAc- $n$-hexaneacetone $=3: 6.5: 0.5)$. Reddish needles $\left(\mathrm{MeOH}-\mathrm{H}_{2} \mathrm{O}\right)$, mp 184$185^{\circ} \mathrm{C} .{ }^{1} \mathrm{H}$ NMR ${ }^{1} \mathrm{H}$ NMR $\left(400 \mathrm{MHz}, \mathrm{CD}_{3} \mathrm{OD}\right): \delta=3.73,(3 \mathrm{H}, \mathrm{s}$, OMe), $7.30\left(2 \mathrm{H}, \mathrm{s}, \mathrm{CH}_{2}\right), 5.82(2 \mathrm{H}, \mathrm{s}, \mathrm{H}-3,5), 6.81(2 \mathrm{H}, \mathrm{d}$, $\left.J=8.8 \mathrm{~Hz}, \mathrm{H}-3^{\prime}, 5^{\prime}\right), 7.13\left(2 \mathrm{H}, \mathrm{d}, J=8.8 \mathrm{~Hz}, \mathrm{H}-2^{\prime}, 6^{\prime}\right) .{ }^{13} \mathrm{C}$ NMR $\left(100 \mathrm{MHz}, \mathrm{CD}_{3} \mathrm{OD}\right): \delta=49.6\left(\mathrm{CH}_{2}\right), 55.6(\mathrm{OMe}), 95.8(\mathrm{C}-3,5)$, $105.2(\mathrm{C}-1), 114.6\left(\mathrm{C}-3^{\prime}, 5^{\prime}\right), 129.3\left(\mathrm{C}-1^{\prime}\right), 131.7\left(\mathrm{C}-2^{\prime}, 6^{\prime}\right), 159.7$ 
(C-4'), $165.8\left(\mathrm{C}-4,166.3(\mathrm{C}-2,6), 204.9(\mathrm{C}=0)\right.$. EIMS m/z: $274[\mathrm{M}]^{+}$, 153 [ring $\mathrm{A}+\mathrm{C}=\mathrm{O}]^{+} .2,34$

\subsubsection{6. $2,4,4^{\prime}, 6$-Tetrahydroxydeoxybenzoin (16)}

$1.61 \mathrm{~g}, 61.9 \%$ (scale: $6.19 \mathrm{mmol}$ ). $\mathrm{Rf}=0.34$ (EtOAc- $n$-hexaneacetone $=4: 5.5: 0.5)$. Yellowish powders $\left(\mathrm{MeOH}-\mathrm{H}_{2} \mathrm{O}\right), \mathrm{mp} 272{ }^{\circ} \mathrm{C}$. ${ }^{1} \mathrm{H}$ NMR (400 MHz, acetone- $\left.d_{6}\right): \delta=4.31\left(2 \mathrm{H}, \mathrm{s}, \mathrm{CH}_{2}\right), 5.93(2 \mathrm{H}, \mathrm{s}$, $\mathrm{H}-3,5), 6.75\left(2 \mathrm{H}, \mathrm{d}, J=8.4 \mathrm{~Hz}, \mathrm{H}-3^{\prime}, 5^{\prime}\right), 7.11(2 \mathrm{H}, \mathrm{d}, J=8.4 \mathrm{~Hz}, \mathrm{H}-$ $\left.2^{\prime}, 6^{\prime}\right), 8.13(1 \mathrm{H}$, br s, phenolic $\mathrm{OH}), 9.25(1 \mathrm{H}, \mathrm{br}$, phenolic $\mathrm{OH})$, $11.74(1 \mathrm{H}$, br s, C-2 OH $) .{ }^{13} \mathrm{C} \mathrm{NMR}\left(100 \mathrm{MHz}\right.$, acetone- $\left.d_{6}\right): \delta=48.6$ $\left(\mathrm{CH}_{2}\right), 95.2(\mathrm{C}-3,5), 104.4(\mathrm{C}-1), 115.1\left(\mathrm{C}-3^{\prime}, 5^{\prime}\right), 127.0\left(\mathrm{C}-4^{\prime}\right)$, $130.9\left(\mathrm{C}-2^{\prime}, 6^{\prime}\right), 156.2\left(\mathrm{C}-4^{\prime}\right), 164.8(\mathrm{C}-4), 164.8(\mathrm{C}-2,4), 203.6$ $(\mathrm{C}=\mathrm{O})$. EIMS $\mathrm{m} / \mathrm{z} 260[\mathrm{M}]^{+}, 153$ [ring $\left.\mathrm{A}+\mathrm{C}=\mathrm{O}\right]^{+} .2,16$

\subsubsection{2,4,6-Trihydroxy-3', $\mathbf{4}^{\prime}$-dimethoxydeoxybenzoin (17)}

$2.03 \mathrm{~g}, 66.8 \%$ (scale: $6.68 \mathrm{mmol}$ ). $R_{\mathrm{f}}=0.31$ (EtOAc- $n$-hexaneacetone $=4: 5.5: 0.5)$. Colorless needles $\left(\mathrm{H}_{2} \mathrm{O}-\mathrm{MeOH}\right)$, mp 188$190{ }^{\circ} \mathrm{C}$; ${ }^{1} \mathrm{H}$ NMR $\left(400 \mathrm{MHz}\right.$, pyridine- $\left.d_{5}\right): \delta=3.76$, (3H, s, OMe), $3.77(3 \mathrm{H}, \mathrm{s}, \mathrm{OMe}), 4.37\left(2 \mathrm{H}, \mathrm{s}, \mathrm{CH}_{2}\right), 5.34(2 \mathrm{H}, \mathrm{s}, \mathrm{H}-3,5), 6.79(1 \mathrm{H}$, dd, $\left.J=2.0,8.0 \mathrm{~Hz}, \mathrm{H}-6^{\prime}\right), 6.84\left(2 \mathrm{H}, \mathrm{d}, J=8.0 \mathrm{~Hz}, \mathrm{H}-5^{\prime}\right), 6.91(1 \mathrm{H}, \mathrm{d}$, $\left.J=2.0 \mathrm{~Hz}, \mathrm{H}-2^{\prime}\right), 9.29(1 \mathrm{H}$, br s, phenolic $\mathrm{OH}), 11.75(2 \mathrm{H}$, br s, C-2, 6 $\mathrm{OH}) .{ }^{13} \mathrm{C}$ NMR (100 MHz, pyridine- $\left.d_{5}\right): \delta=49.0\left(\mathrm{CH}_{2}\right), 55.4$ (OMe), 55.5 (OMe), 95.2 (C-3, 5), 104.4 (C-1), $112.1\left(\mathrm{C}-5^{\prime}\right), 114.3\left(\mathrm{C}-2^{\prime}\right)$, $122.1\left(\mathrm{C}-6^{\prime}\right), 128.8\left(\mathrm{C}-1^{\prime}\right), 148.5\left(\mathrm{C}-4^{\prime}\right), 149.4\left(\mathrm{C}-3^{\prime}\right), 164.8(\mathrm{C}-2,6)$, $164.8(\mathrm{C}-4), 203.3(\mathrm{C}=0)$. EIMS $m / z: 304[\mathrm{M}]^{+}, 153[\mathrm{ring} \mathrm{A}+\mathrm{C}=\mathrm{O}]^{+} .{ }^{34}$

\subsection{Bilogical assays}

\subsubsection{Anti-lipid peroxidation assay}

This assay was determined by the thiocyanate method as described by Mitsuda et al. ${ }^{25}$ In brief, $2 \mathrm{~mL}$ of different concentrations of DOBs and positive controls (Trolox: a water soluble form of tocopherol; vitamin C: ascorbic acid) were taken and well mixed with $3 \mathrm{~mL}$ of linoleic acid emulsion consisting of $2.5 \mathrm{~g}$ Tween-20, $2.5 \mathrm{~g}$ linoleic acid, and $0.04 \mathrm{M}$ of potassium phosphate buffer $(\mathrm{pH}$ 7.0), followed by incubating at $37^{\circ} \mathrm{C}$. After reacting with $\mathrm{FeCl}_{2}$ and thiocyanate at several time intervals, the peroxide value was measured at wavelength $500 \mathrm{~nm}$.

\subsubsection{Metal chelating assay}

The chelating effect of ferrous ions by the DOBs was determined as described previously. ${ }^{27}$ In brief, $1 \mathrm{~mL}$ of DOBs at different concentrations was mixed with $3.7 \mathrm{~mL}$ of methanol and $0.1 \mathrm{~mL}$ of $2 \mathrm{mM} \mathrm{FeCl}_{2}$. The reaction was initiated by the addition of $0.2 \mathrm{~mL}$ of $5 \mathrm{mM}$ ferrozine, followed by shaking vigorously and left to react at room temperature for $10 \mathrm{~min}$. The absorbance was measured at $562 \mathrm{~nm}$. EDTA, a strong metal chelator, was used as a standard metal chelating agent.

\subsubsection{Reducing power assay}

The reducing power of DOBs was determined according to the method of Oyaizu. ${ }^{29}$ In brief, $2.5 \mathrm{~mL}$ of various concentrations of DOBs or positive controls (i.e., Trolox and vitamin C) was mixed with $2.5 \mathrm{~mL}$ of $0.2 \mathrm{M}$ phosphate buffer ( $\mathrm{pH} \mathrm{6.6)}$ and $2.5 \mathrm{~mL}$ of $1 \%$ potassium ferric cyanide. After incubating the mixture at $50{ }^{\circ} \mathrm{C}$ for $20 \mathrm{~min}, 2.5 \mathrm{~mL}$ of $10 \%$ trichloroacetic acid was added, followed by centrifuging at $3000 \mathrm{rpm}$ for $10 \mathrm{~min}$. Five (5) milliliters of the upper layer solution were taken and mixed with $5 \mathrm{~mL}$ distilled water and $1 \mathrm{~mL}$ of $0.1 \% \mathrm{FeCl}_{3}$. The mixture was then measured at absorbance $700 \mathrm{~nm}$.

\subsubsection{ABTS $^{+}$cation radical scavenging assay}

The scavenging activity of $\mathrm{ABTS}^{+}$was measured according to the method described by Re et al. ${ }^{26}$ with some modifications. Briefly, ABTS was dissolved in deionized water to $7 \mathrm{mM}$ in concentration, which was then mixed with $2.45 \mathrm{mM}$ potassium persul- fate. The scavenging activity was determined by mixing with $180 \mu \mathrm{L}$ of ABTS and $40 \mu \mathrm{L}$ of DOBs or negative control (PBS; phosphate buffered saline) or positive controls (i.e., Trolox and vitamin C), followed by measuring at absorbance $734 \mathrm{~nm}$.

\subsubsection{DPPH radical scavenging assay}

This assay was conducted according to the method as described by Wu and Ng. ${ }^{27}$ Briefly, $1 \mathrm{~mL}$ of $0.1 \mathrm{mM}$ DPPH radical solution was mixed with $3 \mathrm{ml}$ of various concentrations of DOBs or Trolox or vitamin $\mathrm{C}$ dissolving in methanol. The mixture was then vortexed vigorously and left for $30 \mathrm{~min}$ at $40^{\circ} \mathrm{C}$ in the dark. For the baseline control, $3 \mathrm{~mL}$ of methanol was used. The absorbance was measured at $517 \mathrm{~nm}$.

\subsubsection{Superoxide anion radical scavenging assay}

The assay of DOBs was conducted according to the method described by Gülçin. ${ }^{28}$ In brief, superoxide radicals were generated in $3 \mathrm{~mL}$ of phosphate buffer $(0.1 \mathrm{M}, \mathrm{pH} 7.4)$ containing $1 \mathrm{~mL}$ of nitroblue tetrazolium (NBT, $300 \mu \mathrm{M}), 1 \mathrm{~mL}$ of PMS $(120 \mu \mathrm{M}), 1 \mathrm{~mL}$ of NADH $(968 \mu \mathrm{M})$ and $1 \mathrm{~mL}$ of DOBs at various concentrations. The mixture was spectrophotometrically measured at $560 \mathrm{~nm}$. Trolox and vitamin $\mathrm{C}$ were used as positive controls.

\subsubsection{Mushroom tyrosinase inhibitory assay}

DOBs selected for this assay are presented in Table 3 and were determined according to the method reported previously. ${ }^{36}$ DOBs and kojic acid (positive control) were dissolved in DMSO/methanol and diluted to various concentrations using potassium phosphate buffer ( $\mathrm{pH} 6.8$ ). The 96 -well plate containing $80 \mu \mathrm{L}$ of L-tyrosine ( $2.0 \mathrm{mM}$ ) and $20 \mu \mathrm{L}$ of various concentrations of DOBs or kojic acid were diluted with buffer to $200 \mu \mathrm{L}$ after adding $20 \mu \mathrm{L}$ of mushroom tyrosinase ( $1000 \mathrm{U} / \mathrm{mL}$, EC 1.14 .18 .1 ). Inhibitory percentage of the test compounds was determined at wavelength $490 \mathrm{~nm}$ after 0.5 , 1.5 and $2.5 \mathrm{~h}$ of incubation.

\section{Acknowledgments}

We are grateful to the partial financial support from the Tajen University and the NMR spectral measurements by Mr. P.L. Lin from the Instrumental Centre of Tajen University. The computer time and facilities provided by the National Center of High-performance Computing are also greatly appreciated.

\section{Supplementary data}

Supplementary data (synthetic procedures and the NMR spectra of all the DOBs) associated with this article can be found, in the online version, at doi:10.1016/j.bmc.2009.05.019.

\section{References and notes}

1. Wähälä, K.; Hase, T. A. J. Chem. Soc., Perkin Trans. 1 1991, 3005.

2. Balasubramanian, S.; Nair, M. G. Synth. Commun. 2000, 30, 469.

3. Balasubramanian, S.; Ward, D. L.; Nair, M. G. J. Chem. Soc., Perkin Trans. 12000 , 567.

4. Wong, E. In The Flavonoids; Harborne, J. B., Mabry, T. J., Mabry, H., Eds.; Academic Press: New York, 1975; p 750. Chapter 14.

5. Wong, E. In The Flavonoids; Harborne, J. B., Mabry, T. J., Mabry, H., Eds.; Academic Press: New York, 1975; p 786. Chapter 14.

6. Heinonen, S.; Hoikkala, A.; Wähälä, K.; Adlercreutz, H. J. Steroid Biochem. Mol. Biol. 2003, 87, 285.

7. Heinonen, S.; Wähälä, K.; Adlercreutz, H. Anal. Biochem. 1999, 274, 211.

8. Coldham, N. G.; Darby, C.; Hows, M.; King, L. J.; Zhang, A. Q.; Sauer, M. J. Xenobiotica 2002, 32, 45.

9. Coldham, N. G.; Howells, L. C.; Santi, A.; Montesissa, C.; Langlais, C.; King, L. J.; Macpherson, D. D.; Sauera, M. J. J. Steroid Biochem. Mol. Biol. 1999, 70, 169.

10. Athar, M.; Back, J. H.; Tang, X.; Kim, K. H.; Kopelovich, L.; Bickers, D. R.; Kim, A. L. Toxicol. Appl. Pharmacol. 2007, 224, 274.

11. Ososki, A. L.; Kennelly, E. J. Phytother. Rev. 2003, 17, 845 
12. Nakamura, Y.; Watanabe, S.; Miyake, N.; Kohno, H.; Osawa, T. J. Agric. Food Chem. 2003, 51, 3309.

13. Rezk, B. M.; Haenen, G. R.; van der Vijgh, W. J.; Bast, A. Biochem. Biophys. Res. Commun 2002, 259, 9 .

14. Huang, Y. C.; Guh, J. H.; Cheng, Z. J.; Chang, Y. L.; Huang, T. L.; Lin, C. N.; Teng, C M. Life Sci. 2001, 68, 2435.

15. Gacche, R. N.; Dhole, N. A.; Kamble, S. G.; Bandgar, B. P. J. Enzyme Inhib. Med. Chem. 2008, 23, 28 .

16. Fokialakis, N.; Lambrinidis, G.; Mitsiou, D. J.; Aligiannis, N.; Mitakou, S.; Skaltsounis, A.-L.; Pratsinis, H.; Mikros, E.; Alexis, M. N. Chem. Biol. 2004, 11, 397.

17. Uckun, F.; Malaviya, R.; Jan, S.-T.; Zhu, D.-M.; Malaviya, R. J. Allergy Clin Immunol. 2000, 105 (1, Part 2), abstr. 1061.

18. Li, H.-Q.; Xue, J.-Y.; Shi, L.; Gui, S.-Y.; Zhu, H.-L. Eur. J. Med. Chem. 2008, 662.

19. Xiao, Z.-P.; Shi, D.-H.; Li, H.-Q.; Zhang, L.-N.; Xu, C.; Zhu, H.-L. Bioorg. Med. Chem. 2007, 15, 3703.

20. Gilgun-Sherki, Y.; Rosenbaum, Z.; Melamed, E.; Offen, D. Pharmacol. Rev. 2002, 54, 271.

21. Cuzzocrea, S.; Riley, D. P.; Caputi, A. P.; Salvemini, D. Pharmacol. Rev. 2001, 53 135.
22. Kirkham, P.; Rahman, I. Pharmacol. Therap. 2006, 111, 476.

23. Winkler, C.; Frick, B.; Schroecksnadelm, K.; Schennach, H.; Fuchs, D. Food Chem Toxicol. 2006, 44, 2003

24. Lupo, M. P. Clin. Dermatol. 2001, 19, 467

25. Mitsuda, H.; Yuasumoto, K.: Iwami, K. Ei yo to Shokuryo 1996, 19, 210.

26. Wu, S. J.; Ng, L. T. LWT-Food Sci. Technol. 2008, 41, 323.

27. Oyaizu, M. Jpn. J. Nutr. 1996, 44, 307.

28. Re, R.; Pellegrini, N.; Proteggente, A.; Pannala, A.; Yang, M.; Rice-Evans, C. Free Radical Biol Med 1999, 26, 1231.

29. Gülcin, I. Toxicology 2006, 217, 213

30. Ohguchi, K.; Tanaka, T.; Ito, T.; Iinuma, M.; Matsumoto, K.; Akao, Y.; Nozawa, Y. Biosci. Biotechnol. Biochem. 2003, 67, 1587.

31. Khatib, S.; Nerya, O.; Musa, R.; Tamir, S.; Peter, T.; Vaya, J. Med. Chem. 2007, 50 2676.

32. Khatib, S.; Nerya, O.; Musa, R.; Shmuel, M.; Tamir, S.; Vaya, J. Bioorg. Med. Chem. 2005, 13, 433.

33. Nerya, O.; Musa, R.; Khatib, S.; Tamir, S.; Vaya, J. Phytochemistry 2004, 65, 1389

34. Jha, H. C.; Zilliken, F.; Offermann, W.; Breitmaier, E. Can. J. Chem. 1981, 59, 2266.

35. Parmar, V. S.; Singh, S.; Jain, R. Ind. J. Chem. 1987, 26, 484.

36. Ko, H. H.; Chang, W. L.; Lu, T. M. J. Nat. Prod. 2008, 71, 1930. 